BMC

Cancer

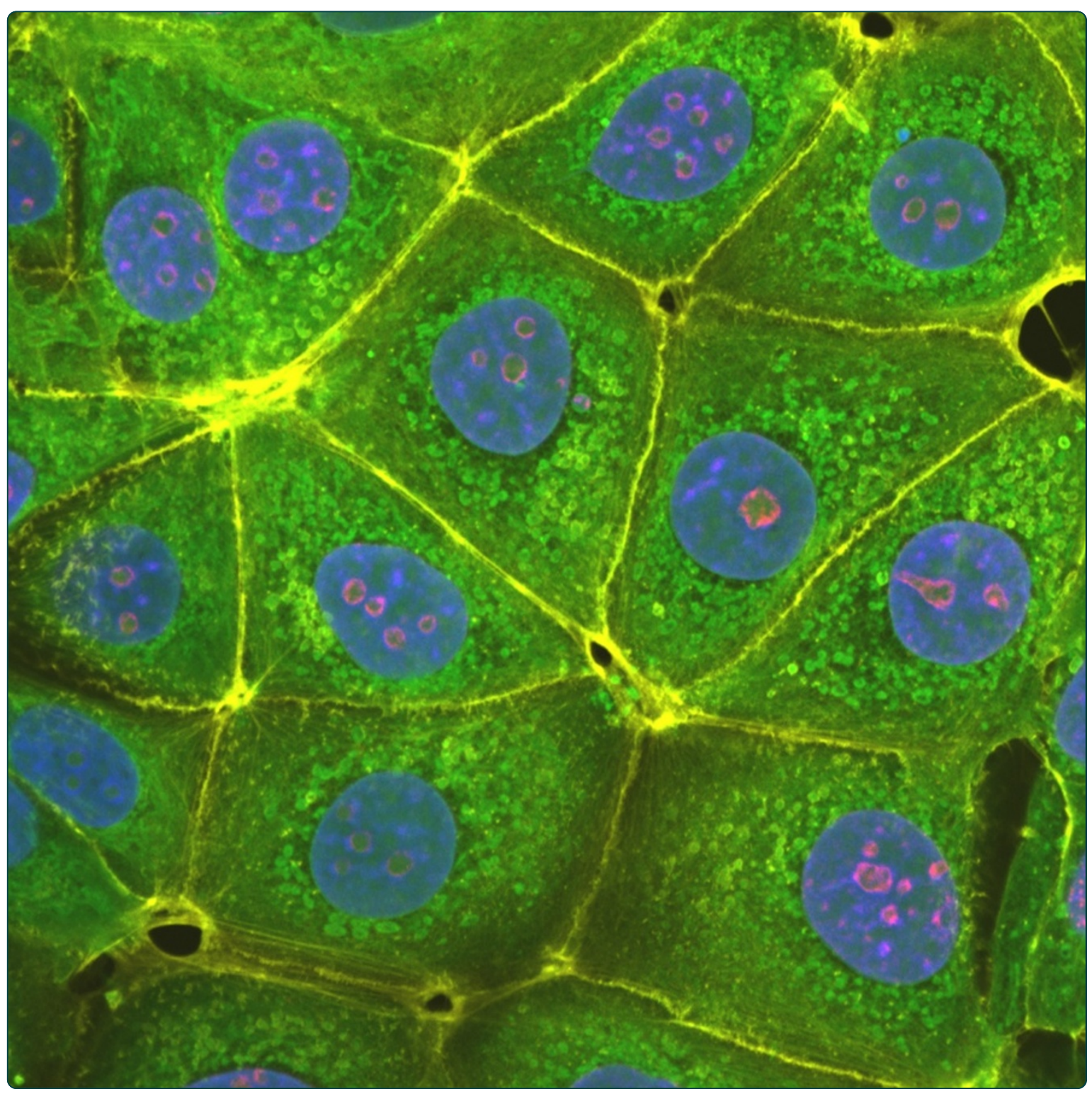

Nuclear location of tumor suppressor protein maspin inhibits proliferation of breast cancer cells without affecting proliferation of normal epithelial cells

Machowska et al. 


\title{
Nuclear location of tumor suppressor protein maspin inhibits proliferation of breast cancer cells without affecting proliferation of normal epithelial cells
}

Magdalena Machowska', Katarzyna Wachowicz ${ }^{1,3}$, Mirosław Sopel ${ }^{2}$ and Ryszard Rzepecki ${ }^{\text {* }}$

\begin{abstract}
Background: Maspin, which is classified as a tumor suppressor protein, is downregulated in many types of cancer. Several studies have suggested potential anti-proliferative activity of maspin as well as sensitizing activity of maspin for therapeutic cytotoxic agents in breast cancer tissue culture and animal models. All of the experimental data gathered so far have been based on studies with maspin localized cytoplasmically, while maspin in breast cancer tumor cells may be located in the cytoplasm, nucleus or both. In this study, the effect of maspin cytoplasmic and nuclear location and expression level on breast cancer proliferation and patient survival was studied.
\end{abstract}

Methods: Tissue sections from 166 patients with invasive ductal breast cancer were stained by immunohistochemistry for maspin and Ki-67 protein. The localization and expression level of maspin were correlated with estimated patient overall survival and percent of Ki-67-positive cells. In further studies, we created constructs for transient transfection of maspin into breast cancer cells with targeted cytoplasmic and nuclear location. We analyzed the effect of maspin location in normal epithelial cell line MCF10A and three breast cancer cell lines - MCF-7, MDA-MB-231 and SKBR-3 - by immunofluorescence and proliferation assay.

Results: We observed a strong positive correlation between moderate and high nuclear maspin level and survival of patients. Moreover, a statistically significant negative relationship was observed between nuclear maspin and Ki-67 expression in patients with invasive ductal breast cancer. Spearman's correlation analysis showed a negative correlation between level of maspin localized in nucleus and percentage of Ki-67 positive cells. No such differences were observed in cells with cytoplasmic maspin. We found a strong correlation between nuclear maspin and loss of Ki-67 protein in breast cancer cell lines, while there was no effect in normal epithelial cells from breast. The anti-proliferative effect of nuclear maspin on breast cancer cells was statistically significant in comparison to cytoplasmic maspin.

Conclusions: Our results suggest that nuclear maspin localization may be a prognostic factor in breast cancer and may have a strong therapeutic potential in gene therapy. Moreover, these data provide a new insight into the role of cytoplasmic and nuclear fractions of maspin in breast cancer.

Keywords: Maspin, Breast cancer, Nuclear maspin, Cell proliferation, Ki-67

\footnotetext{
* Correspondence: rzepecki@ibmb.uni.wroc.pl

1 Laboratory of Nuclear Proteins, Faculty of Biotechnology, University of

Wroclaw, 63/77 Przybyszewskiego Street, 51-148 Wrocław, Poland

Full list of author information is available at the end of the article
} 


\section{Background}

Maspin (Mammary Serine Protease Inhibitor) was first identified in normal mammary glands and breast cancer cells. Based on structural homology, maspin belongs to the serpin superfamily (serpin b5) [1]. Since serpin b5 has no inhibitory activity against serine proteases, its role in cells is not fully understood [2].

In normal mammary glands, maspin is expressed, at a high level, in myoepithelial cells, while it is not found in luminal cells $[1,3]$. Maspin may be located in cytoplasm, nucleus, at the cell surface and in extracellular matrix of myoepithelial cells in normal mammary glands [4]. However, there have been no specific domains or sequences identified that may ensure maspin nuclear localization or secretion. Maspin is responsible for cell adhesion and mobility during embryogenesis and mammary gland development [5]. Maspin is also important in the development of the mammary gland. At the early stage of lactation, maspin causes a lower level of milk proteins, including casein and WAP (whey acidic protein) [6].

Maspin is classified as a class II tumor suppressor. Maspin demonstrates proapoptotic, antimetastatic and antiangiogenic properties, exerting an inhibitory effect on tumor cell survival, mobility, invasiveness and metastasis ability, and also reduces the tumor tissue vascularization [7-10]. In many studies, it has been found that a decreased level of maspin causes cancer progression and transition from non-invasive to invasive cancer $[11,12]$. In vitro studies showed that in primary cell lines derived from tumors maspin is expressed, while after several passages the maspin level decreases until complete loss $[7,13]$. In secondary breast cancer cell lines maspin is absent [14]. Clinical data indicate a positive correlation between higher maspin expression level and lower degree of differentiation, lower grade of tumor and improved survival of patients $[10,15]$.

Despite these data, there are some controversial and contradictory data about maspin prognostic significance and importance of its expression. In many cancer studies, including those related to breast cancer, a negative and positive correlation are described with reference to high or low maspin expression level as a prognostic factor of tumor development [16-19].

Many reports have suggested that biological significance, activity and clinical implications of maspin in various types of cancer depend on its subcellular localization [19-22]. In many types of cancers, including breast, ovarian, lung, larynx, renal and colon cancer, there has been indicated a positive correlation between nuclear maspin location and molecular markers of good prognosis, benign instead of malignant form of cancer, better patient survival and long-term remission [19,20,23-26]. However, the significance of nuclear maspin localization in cancer is still not clear enough to use maspin localization pattern as an unquestioned diagnostic or prognostic factor. Maspin's mechanism of action, especially its nuclear fraction, is not very well understood and requires further examination for better understanding. Recently, a few attempts have been made to clarify this controversy of anticancer activity and molecular mechanism of action of maspin using different models [22,27-29] but they have not clarified fully the essential question of the potential different activities of cytoplasmic and nuclear fraction of maspin, because in studies performed so far maspin was mainly localized in cytoplasm or ubiquitously in cytoplasm and cell nucleus [22,30,31].

That is why we made an attempt to develop a breast cancer tissue culture model system for studies of function of cytoplasmic and nuclear maspin independently. This breast cancer cell line model system together with clinical data from the patients allowed us to resolve the effect of nuclear and cytoplasmic maspin in breast cancer on proliferation and its potential as a genetic drug in breast cancer gene therapy.

\section{Methods}

\section{Patient samples and ethical issues}

Breast tumor tissue sections for statistical analysis were taken intraoperatively from 166 women diagnosed with invasive ductal breast cancer. For visualization of maspin location during cancerogenesis (see Figure 1) breast tumor sections were stained also from material taken from women diagnosed with other stages of cancer: early stage of ductal breast cancer, ductal carcinoma in situ, early stage of invasive breast cancer. Slices of breast tumor tissue were collected in accordance and with the recommendations of the: "Bioethical Committee of the Lower Silesian Oncology Center". Research was performed on archived, fixed and paraffin-embedded breast tissue specimens obtained during breast cancer surgery. According to Polish regulations we do not need to obtain patients consent for studies on archived tissue specimens. Sample processing, data processing and analyses were performed in full compliance with all bioethical regulations and in accordance with Polish law. Bioethical Committee of the Lower Silesian Oncology Center approved the study.

$4 \%$ formalin-fixed and paraffin-embedded samples for histopathological examination were routinely stained with hematoxylin and eosin. Histological evaluation of specimens was made by two independent pathologists. The characteristics of the patients are shown in Table 1. Adjacent slices of the same paraffin blocks were used for immunohistochemistry.

\section{Immunohistochemistry}

Paraffin sections were placed on Superfrost + slides, deparaffinized in xylene, rehydrated in a series of decreasing concentrations of ethanol and washed in 

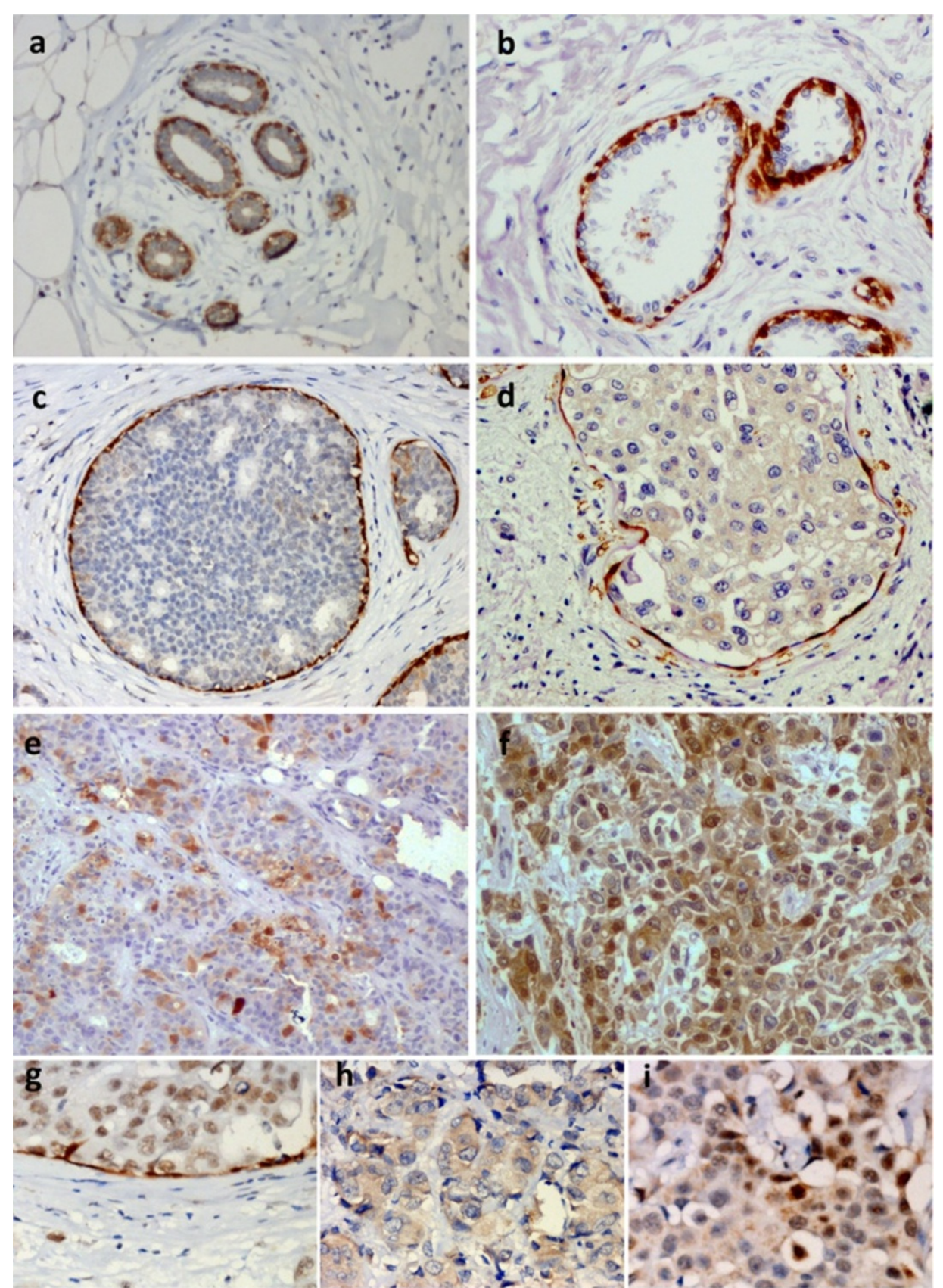

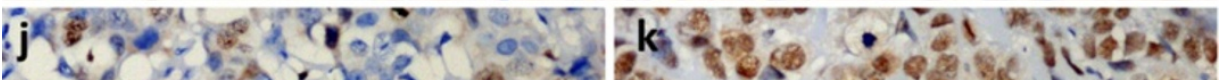

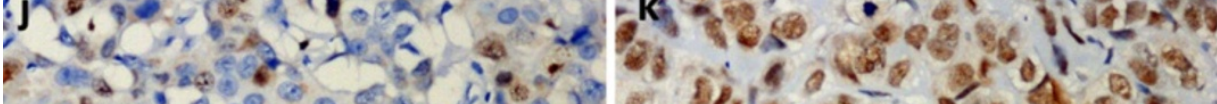

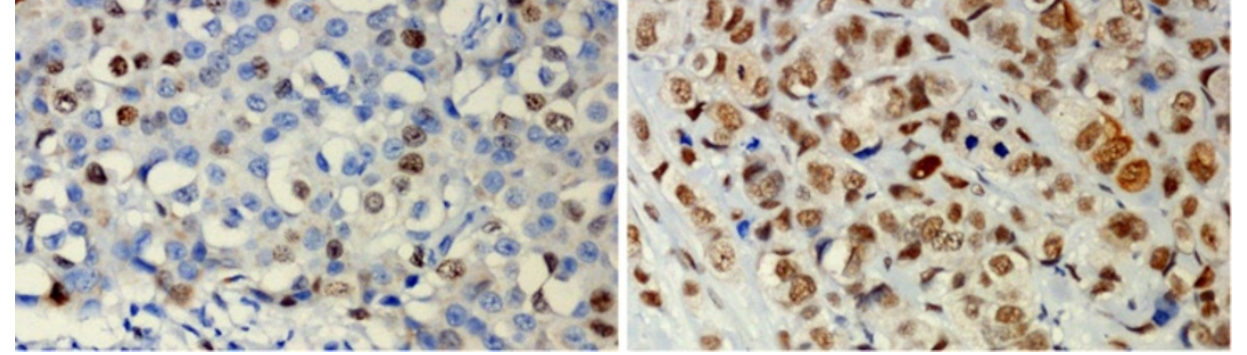

Figure 1 (See legend on next page.) 
(See figure on previous page.)

Figure 1 Immunohistochemical staining of breast cancer specimens from patients. Staining for: maspin (a-i) and Ki-67 (j, k); a - maspin localization in normal human mammary gland; b-f - maspin localization in different stages of breast cancer, as follows: early stage of ductal breast cancer, ductal carcinoma in situ, early stage of invasive breast cancer, invasive breast cancer (e, f); $\mathbf{g}$-i - subcellular maspin localization in breast cancer, as follows: nuclear, cytoplasmic, mixed; $\mathbf{j}$ - low grading tumor with low percentage of Ki-67 positive cells; k - breast cancer with high percentage of Ki-67 positive cells in malignant cancer.

phosphate buffered saline (PBS). After antigen retrieval

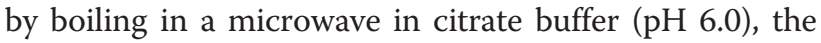
endogenous peroxidase activity was blocked by incubating sections with $3 \% \mathrm{H}_{2} \mathrm{O}_{2}$ solution for 30 minutes.

Slices were incubated for one hour at room temperature with primary antibodies diluted in background reducing buffer (DakoCytomation): mouse anti-human maspin (clone G167-7, BD Pharmingen), dilution 1:400 or mouse antiKi-67 (clone MIB-1, DakoCytomation), dilution 1:10. After washing three times with PBS for 5 minutes, slices were incubated for $15 \mathrm{~min}$ with secondary, biotinylated antibody, followed by $30 \mathrm{~min}$ incubation with streptavidinhorseradish peroxidase (DakoCytomation). Color was developed with 3,3'-diaminobenzidine (DAB) for 3-7 minutes. Nuclei were stained with Mayer's hematoxylin.

To evaluate maspin expression, a semiquantitative method [32] was used to determine reaction intensity and percentage of positive cells from three representative fields of the specimen at $40 \times$ magnification. Specimens were scored according to percentage: $1-5 \%-1$ point, $6-50 \%-2$ points, $>50 \%-3$ points and reaction intensity: weak -1 point, moderate -2 points, strong 3 points. Points for both percentage and intensity were added and specimens were categorized into four groups: negative reaction -0 points $(0$ points for percentage and intensity), weak reaction -1 point (1-2 points), moderate reaction -2 points (3-4 points), strong reaction -3 points (5-6 points). Evaluation of maspin expression was conducted independently for the cytoplasm and the nucleus using the same procedure.

To evaluate the proliferative status, three representative fields with the typical signal from Ki-67 antigen was chosen [33]. At 40× magnification, nuclei showing expression of Ki-67 antigen in relation to all nuclei were counted. Proliferative status of tumors was evaluated as the percentage of positive cells and classified into two groups: less than $20 \%$ and more than $20 \%$ (according to the limit value of predictive and prognostic assessment of Ki-67 expression in breast cancer).

\section{Cell culture}

Human breast cancer cell line MCF-7 was cultured in Eagle's medium (EMEM, Lonza) and MDA-MB-231 and SKBR-3 cell lines were cultured on Dulbecco's modified Eagle's medium (DMEM with low glucose, Lonza) supplemented with $10 \%$ fetal bovine serum (Sigma), 1\% Glutamax (Gibco) and 1\% antibiotic/antimycotic (Gibco). MCF10A cell line was cultured on DMEM/F12 medium (medium mixture, Lonza) supplemented with $5 \%$ horse serum (Gibco), 1\% Glutamax (Gibco), 1\% antibiotic/antimycotic (Gibco), $20 \mathrm{ng} / \mathrm{ml}$ epidermal growth factor (Sigma), $0.5 \mu \mathrm{g} / \mathrm{ml}$ hydrocortisone (Sigma), $100 \mathrm{ng} / \mathrm{ml}$ cholera toxin (Sigma) and $10 \mu \mathrm{g} / \mathrm{ml}$ insulin (Sigma). MCF-7 (ATTC HTB-22), SKBR-3 (ATTC HTB-30), MDA-MB231 (ATTC HTB-26) and MCF10A (ATTC CRL-10317) cell lines were kindly provided by Dr Paweł Surowiak (Wrocław Medical University) and Prof. Hermann Lage (Institute of Pathology, Charite Campus Mitte, Humboldt University, Berlin). MCF-7 stable cell lines expressing enhanced green fluorescent protein (EGFP) and maspinEGFP were cultured in supplemented Eagle's medium with G418 antibiotic in a final concentration of $150 \mu \mathrm{g} / \mathrm{ml}$. All cell lines were maintained at $37^{\circ} \mathrm{C}$ in $5 \% \mathrm{CO}_{2}$.

\section{Plasmid construction}

Control plasmid pEGFP-C1 ensuring expression of EGFP was purchased from Clontech. Expression vector

Table 1 Patients' characteristics $\mathrm{N}=166$

\begin{tabular}{lll}
\hline Characteristic & N & \% \\
\hline Age & 22 & 13.3 \\
$<=50$ & 42 & 25.3 \\
$51-60$ & 57 & 34.3 \\
$61-70$ & 45 & 27.1 \\
$>70$ & & \\
\hline Tumor (T) & 68 & 41 \\
T1 & 40 & 24.1 \\
T2 & 34 & 20.5 \\
T3 & 24 & 14.4 \\
T4 & & \\
\hline Lymph nodes (N) & 59 & 35.5 \\
N0 & 107 & 64.5 \\
N1 & & \\
\hline Metastasis (M) & 124 & 74.7 \\
M0 & 42 & 25.3 \\
M1 & & 34.4 \\
\hline Grade (G) & 57 & 32.5 \\
G1 & 54 & \\
G2 & 55 & \\
G3 & & \\
\hline
\end{tabular}


with maspin cDNA sequence (NM_002639) was constructed based on pReceiver M03 (GeneCopoeia). In order to obtain nuclear localization of maspin with fusion protein EGFP, the nuclear localization signal (NLS) was inserted between the sequences encoding maspin and EGFP. NLS was inserted by site-directed mutagenesis using QuikChange XL kit (Stratagene). Sequences of primers are the following: (forward/reverse) 5' -CTCCTTACGGTCATCCA AAAAAGAAGAGAAAGGTCATGGCTAGCGTGAGC-3'; 5'-GCTCACGCTAGCCATGACCTTTCTCTTCTTTTT TGGATGACCGTAAGGAG-3'. The amino acid sequence of NLS is PKKKRKV.

\section{Stable and transient cell transfection}

For generation of stable cell lines expressing EGFP, maspin-EGFP and maspin-NLS-EGFP, MCF-7 cells were plated on a $10 \mathrm{~cm}$ cell culture dish and after 24 hours transfected with complexes of plasmid DNA and MetafectenePro (Biontex). Six hours later cell culture medium was removed and replaced with complete medium and after 48 hours the post-transfection medium was replaced with complete selection medium containing antibiotic G418 to a final concentration of $400 \mu \mathrm{g} / \mathrm{ml}$. The selection was monitored by EGFP expression and negative cell death and G418 concentration was gradually reduced.

For transient transfection to immunofluorescence analysis breast cancer cells were plated on a 24-well plate 24 hours before transfection. Six hours after transfection with complexes of MetafectenePro and plasmid DNA medium was replaced with fresh complete medium. After appropriate time cells were fixed and stained as described below.

\section{Immunofluorescence}

For immunofluorescence experiments, cells were plated on glass coverslips, fixed in $4 \%$ paraformaldehyde for 20 minutes and permeabilized with $0.5 \%$ Triton X-100 in PBS. Fixed cells were incubated in primary antibody solution overnight at $4^{\circ} \mathrm{C}$, washed with PBS, and incubated for 1 hour with secondary antibody solution at room temperature and washed again in PBS. Coverslips were mounted on glass slides using DABCO mounting medium (Fluka) with DAPI. Staining was visualized on a Zeiss 510 Meta confocal microscope using the 63X objective. Primary antibodies used for staining were mouse anti-human maspin (BD Pharmingen, 1:25), mouse antihuman Ki-67 (DakoCytomation, 1:50), rabbit anti-human lamin C (a kind gift from prof. C.J Hutchison, 1:20). Secondary antibodies were donkey anti-mouse conjugated with TRITC and donkey anti-rabbit conjugated with Cy5 (both from Jackson ImmunoResearch). After 24 hours to 120 hours following transfection, EGFP-expressing cells were counted for expression of Ki-67 antigen in five to ten fields of view and the Ki-67-positive subpopulation was calculated as the percentage of all transfected cells.

\section{Cell proliferation assay}

For cell proliferation assay cells were plated on a $10 \mathrm{~cm}$ cell culture dish and after 24 hours transfected with complexes of plasmid DNA and MetafectenePro (Biontex). Medium was replaced every three days with complete medium (without G418). After 24 hours to 9 days following transfection EGFP-expressing cells and all cells were counted in four fields of view and the EGFP-positive subpopulation was calculated as the percentage of all cells.

\section{Statistical analysis}

SPSS software (SPSS version 17.0., Chicago, Illinois, USA) was used for statistical analysis of histopathological results. In order to analyze the correlation between the maspin protein level in cytoplasm and/or nucleus and the presence of Ki-67 antigen, contingency tables were used. Statistical significance of differences was assessed using the Pearson's chi-square test or, if the assumptions were not met, Fisher's exact test estimated with simulation methods. The correlation was evaluated by Spearman's test. Significance was defined at the level of P-value $\leq 0.05$ by the two-tailed test. Overall survival was estimated by the Kaplan-Meier method. The logrank test (the Mantel-Cox test) was used to evaluate statistical differences between two curves (for cytoplasmic pool of maspin and nuclear pool of maspin).

Microsoft Office Excel 2003 was used for statistical analysis of data obtained from experiments on cell lines. To evaluate the significance of differences between control and experimental groups the two-tailed Student's $t$ test was used.

\section{Results}

Maspin expression and localization in normal and cancer tissue from breast

In normal breast tissue, maspin is expressed in myoepithelial cells (Figure 1a). During cancer development, there is a decline in maspin level in myoepithelial cells and maspin protein is expressed in other cells (Figure 1b-f). Breast cancer cells showed nuclear, cytoplasmic or mixed maspin location (Figure 1g-i).

In order to analyze the subcellular location and assess the level of expression of maspin in normal and tumor tissues of breast, a collection of tissue sections from 166 patients with invasive ductal breast cancer was studied using immunohistochemistry. The maspin-specific staining intensity in ductal breast cancer specimens was compared with staining of myoepithelial cells from regions of normal mammary tissue (Figure 1a) and cancer in situ specimens (Figure 1b,c). The staining intensity in myoepithelial cells was generally stronger than in breast cancer tissue. 
The intensity and subcellular distribution of maspin protein were assessed and counted in specimens of breast cancer tissues. Positive staining for maspin was observed in 148 cases (89.2\%) and lack of this protein in 18 cases $(10.8 \%)$. In the majority of cases $(\mathrm{N}=91 ; 54.8 \%)$ mixed nuclear and cytoplasmic maspin location was observed. In Tables 2 and 3, the distribution of maspin staining localization and intensity is shown. These data indicate that breast cancer specimens showed a heterogeneous level of maspin protein as well as various levels of maspin fraction in cytoplasm and nuclei and that this heterogeneity of maspin level and location should be taken into the future considerations and statistical analyses. Moderate and high levels of nuclear maspin correlate with better prognosis for patients.

\section{Correlation between maspin expression level, location and proliferation status and prognosis for patients}

The data about level of maspin and amount of maspin in particular subcellular locations were analyzed with respect to patient survival rate as well as proliferation status of the cancer cells from patients. The analyses of expression of Ki-67 protein (typical proliferation marker used in cancer diagnosis) in particular cells were performed in parallel in order to assess the proliferation status of cancer cells (Figure 2c,d) [34,35]. Figure 1, sections j and $\mathrm{k}$ demonstrate low grading tumor and high grading tumor (according to Nottingham scale) with low and high percentage of $\mathrm{Ki}-67$ positive cells respectively.

For Kaplan-Meier analyses of survival of patients with breast cancer, samples were divided into two groups representing the subcellular status of maspin - cytoplasmic or nuclear - and the level of protein in particular fractions: low level or lack of protein and moderate and high level of protein (Figure 2a,b). Such organization of data allowed us to demonstrate the strong positive correlation between high nuclear maspin level and the survival of patients. Negative prognosis was associated with high level of cytoplasmic maspin while lack or low level of cytoplasmic maspin correlated with better prognosis than high cytoplasmic maspin.

In order to analyze the correlation between maspin location and Ki-67 protein expression (proliferation status), specimens were divided and categorized into two groups: less than $20 \% \mathrm{Ki}-67$ positive cells (86, 51.8\%) and more than $20 \%(80,48.2 \%)$ (Figure $2 \mathrm{c}, \mathrm{d})$. No significant relationship $(\mathrm{p}=0.118)$ was observed between

Table 2 Maspin localization in patients' specimens

\begin{tabular}{ll}
\hline Maspin localization & Number of cases \\
\hline Mixed & $91(54.8 \%)$ \\
Cytoplasmic & $22(13.3 \%)$ \\
Nuclear & $35(21.1 \%)$ \\
\hline
\end{tabular}

Table 3 Maspin intensity of staining

\begin{tabular}{lll}
\hline Maspin staining intensity & Cytoplasm & Nucleus \\
\hline Lack & $54(32.5 \%)$ & $38(22.9 \%)$ \\
Weak & $27(16.3 \%)$ & $35(21.1 \%)$ \\
Moderate & $71(42.8 \%)$ & $84(50.6 \%)$ \\
Strong & $14(8.4 \%)$ & $9(5.4 \%)$ \\
\hline
\end{tabular}

cytoplasmic maspin and Ki-67 expression. Moreover, there was no significant correlation between cytoplasmic maspin and percentage of Ki-67 positive cells in the two groups (Spearman's correlation $\mathrm{r}=0.121$; $\mathrm{p}=0.124$ ).

There was a statistically significant relationship observed between nuclear maspin and Ki-67 expression $(\mathrm{p}<0.001)$. Spearman's correlation analysis showed a negative correlation between level of maspin localized in nucleus and percentage of Ki-67 positive cells $(r=0.771$; $\mathrm{p}<0.001$ ). In specimens in which less than $20 \%$ of cells expressed Ki-67, most cells showed moderate or strong staining intensity of nuclear maspin. Most cases of lack or weak staining intensity of nuclear maspin were observed in the second group - more than $20 \%$ of Ki-67 positive cells.

\section{Cell culture model for studies of maspin's subcellular fraction anticancer activity}

Generation of cancer cells or cancer cell lines with maspin located in cytoplasm or nucleus seemed to be the best way to evaluate maspin localization influence on cell proliferation and to compare in vitro results to clinical data. Since the size and the structure of maspin theoretically allows maspin to passively diffuse through nuclear pore complexes (NPCs) (with all possible disadvantages of such diffusion taking place), we decided to use maspin fusion proteins with EGFP. We aimed at selecting MCF-7 breast cancer cell lines stably expressing maspin-EGFP fusion protein as a model for cytoplasmic maspin and maspin-NLS-EGFP fusion protein as a model for nuclear maspin. As an additional control we intended to select an EGFP protein expressing MCF-7 cell line. According to our expectations MCF-7 cells transfected with maspin-EGFP construct showed maspin-EGFP location exclusively in cytoplasm while cells transfected with maspin-NLS-EGFP construct showed nuclear accumulation of the protein (Figure 3c). A weak signal from cytoplasm from maspin-NLS-EGFP protein may result from newly synthesized protein not yet transported into the nucleus and/or actively stopped in the cytoplasm by interaction with other proteins. Cells transfected with EGFP protein showed mixed nuclear and cytoplasmic location of this protein (Figure 3c). All of our attempts to generate stable cell lines expressing maspin-NLS-EGFP protein failed. All cells died within 2-3 weeks time after transfection, while we had no problems with selection of 


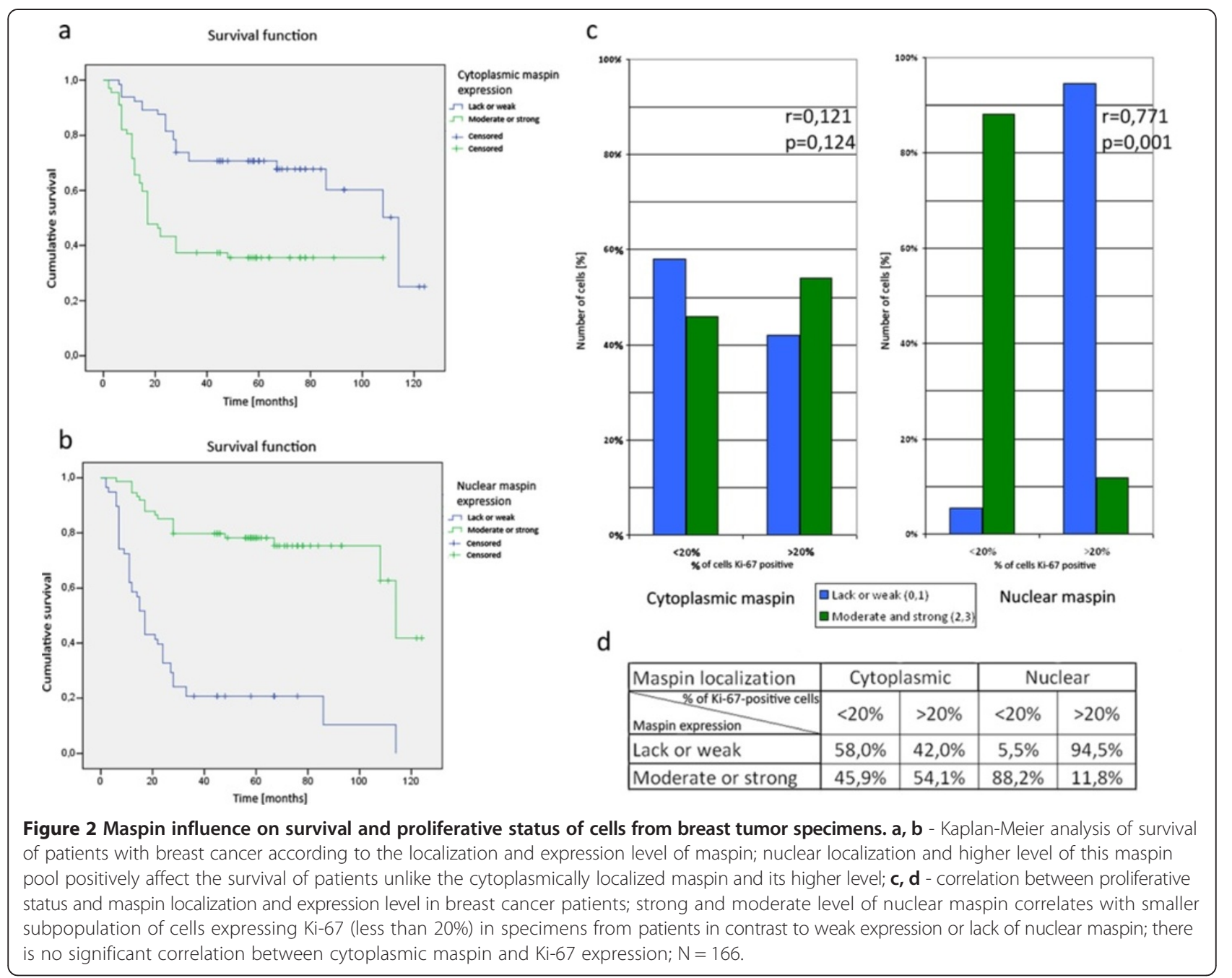

many cell lines stably expressing maspin-EGFP protein and EGFP protein (Figure 3d). This suggested that nuclear location of maspin is toxic for MCF-7 breast cancer cells during longer periods of time while cytoplasmic maspinbearing cells could survive and proliferate.

\section{Maspin location and proliferation of transfected MCF-7 cells}

Since we failed to select stable cell line expressing maspin-NLS-EGFP we were forced to perform further experiments on transiently transfected cells. We decided to analyze the proliferation rate and phenotype of MCF7 cells expressing EGFP protein, cytoplasmic maspin and nuclear maspin at various time points after transfection between $24 \mathrm{~h}$ and $120 \mathrm{~h}$ (1-5 days). Figure 4a,b demonstrates the typical phenotypes of MCF-7 cells transiently transfected with plasmids coding for EGFP, maspin-EGFP and maspin-NLS-EGFP proteins after $48 \mathrm{~h}$ and $96 \mathrm{~h}$ as the most essential for analyses. At the first time points $(24-72 \mathrm{~h})$ cells with cytoplasmic maspin and nuclear maspin showed similar phenotype with respect to size and shape (Figure $4 \mathrm{a}-48 \mathrm{~h}$ ). At time points of 72 up to $120 \mathrm{~h}$ we started to observe a decrease in the number of cells expressing Ki-67 protein in MCF-7 cells with nuclear maspin (Figure 4b-96 h). Figure 4c summarizes the general trend observed in analyzed cells expressing nuclear maspin. Since Ki-67 protein is a marker of proliferation we analyzed the proliferation rate and performed statistical analyses of Ki-67 protein expression in transfected MCF-7 cells.

Cell populations of the attached, transfected and nontransfected cells were daily counted for 9 days and then the percent of transfected cells in comparison to all cells was calculated (Figure 5a,b). The efficiency of transfection in all three cases was about 35\% (after 24 hours). After 48 hours, there was an increase in percentage of EGFP transfected cells and a decrease in the maspinEGFP and maspin-NLS-EGFP subpopulation. From 24 and 48 hours after transfection the percentage of cells expressing maspin-EGFP and maspin-NLS-EGFP decreased 
b

a

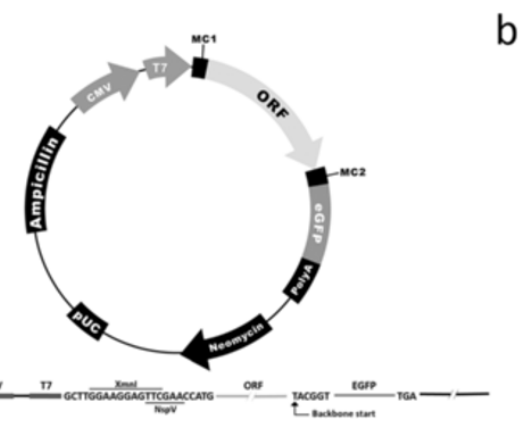

C

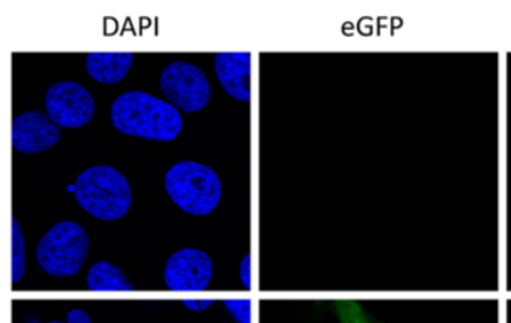

MCF-7-

eGFP

MCF-7

control
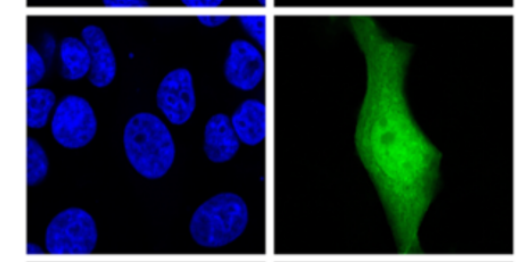

MCF-7-

maspin-

eGFP
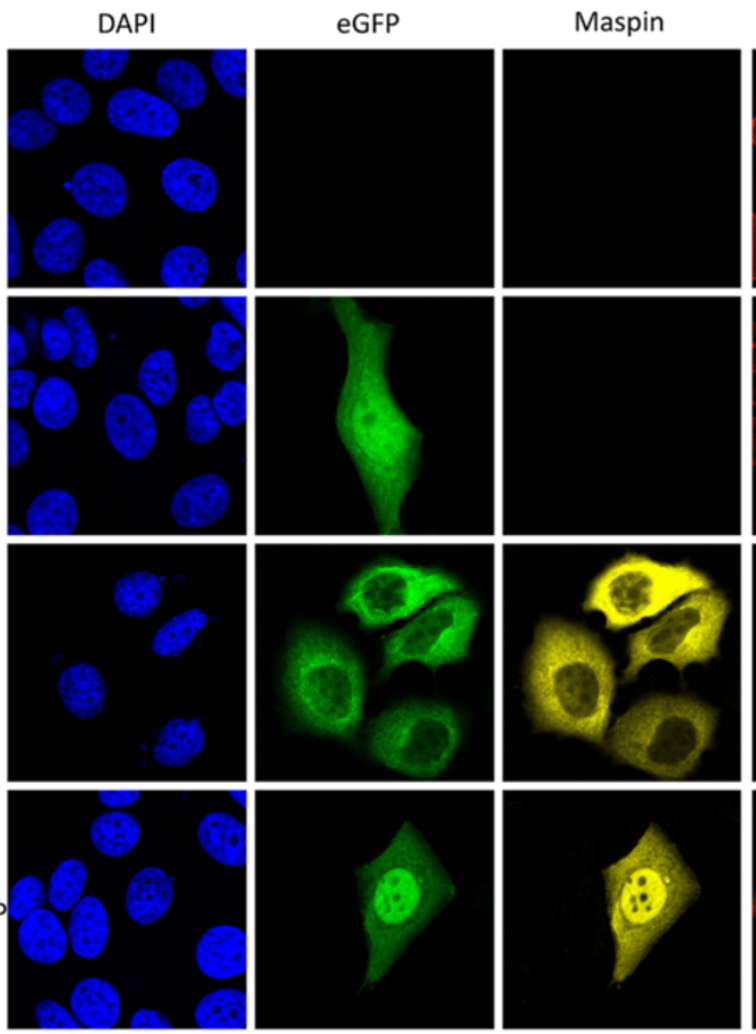

MCF-7-

maspin-

NLS-eGFP
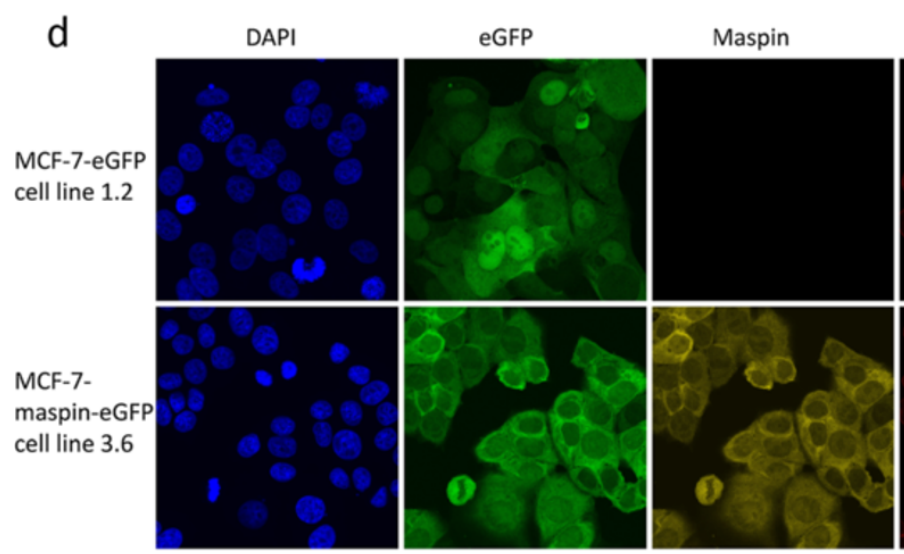

Lamin C
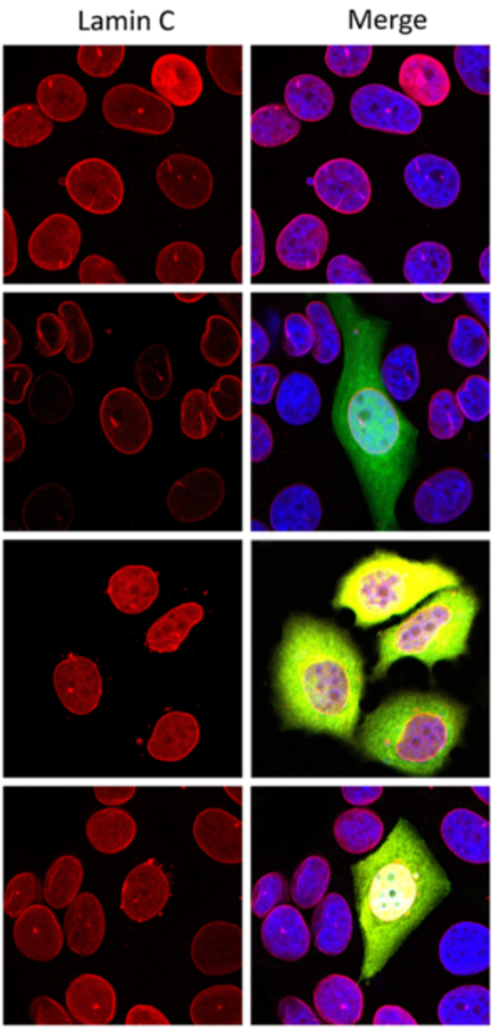

Figure $\mathbf{3}$ (See legend on next page.) 
(See figure on previous page.)

Figure 3 A tissue culture model system for studies of location-dependent maspin's effect on breast cancer cells. a - pReceiver M03 plasmid map in which the sequence of maspin (NM_002639) was cloned; $\mathbf{b}$ - sequences of primers for mutagenesis to the nuclear localization signal (NLS) insertion; c - transient transfection of MCF-7 cells with three plasmids: pEGFP, Msp-EGFP and Msp-NLS-EGFP, maspin staining pattern confirms proper localization in transfected cells; $\mathbf{d}$ - stable cell lines: MCF-7 EGFP clone 1.2 expressing EGFP, MCF-7 maspin-EGFP clone 3.6 expressing maspin with fusion protein EGFP localized in cytoplasm; generation of cell line with nucleus-localized maspin failed because of death of all transfected cells

rapidly. The high increase of percentage of EGFPexpressing cells between 24 and $48 \mathrm{~h}$ was a result of increased efficiency of production of EGFP protein in transfected cells above the detection level and a lower level of overall transfection toxicity.

Until the third day (up to $72 \mathrm{~h}$ ) after transfection, a decrease of percent of transfected cells (for all plasmids) was a net result of cell death and higher proliferation rate of untransfected cells. After that time, new colonies expressing transfection marker (EGFP) appeared in EGFP and maspin-EGFP transfected cells. However, there was no new colony formation observed in maspinNLS-EGFP cells. After the third day, a further decrease of percent of transfected cells was still mainly caused by a higher proliferation rate of non-transfected cells. Significant differences in proliferation were noticeable separately between EGFP and maspin-EGFP and EGFP and maspin-NLS-EGFP. Statistically significant differences between maspin-EGFP and maspin-NLS-EGFP were observed only at $96 \mathrm{~h}$ and $144 \mathrm{~h}$ after transfection (Figure 5b).

We performed statistical analyses of the amount of cells expressing Ki-67 protein among MCF-7 cells expressing EGFP and cytoplasmic and nuclear maspin (Figure $5 \mathrm{c}, \mathrm{d}$ ). We found a strong correlation between nuclear maspin and disappearance of Ki-67 protein at time points starting from $72 \mathrm{~h}$. No correlation was found for cytoplasmic maspin and EGFP protein. This indicates that nuclear maspin inhibits proliferation of MCF-7 breast cancer cell lines starting from $72 \mathrm{~h}$ by mechanisms triggering degradation or inhibition of expression of Ki-67 protein. This implies that only nuclear but not cytoplasmic maspin shows this anti-proliferative activity. These data also are in perfect agreement with the nuclear maspin prognostic marker for patients with breast cancer.

\section{Nuclear maspin shows its anti-proliferative activity in other breast cancer cell lines}

In order to analyze the potential benefits for use of nuclear maspin as an anti-cancer genetic drug we decided to use additional breast cancer cell lines. Up to now we have tested the effect of maspin on MCF-7 breast cancer cell line $(\mathrm{ER}+, \mathrm{PR}+, \mathrm{HER} 2-)$. For our next studies we have chosen SKBR-3 cell line (ER-, PR-, HER2 +) and the highly aggressive, triple negative MDA-MB-231 cell line (ER-, PR-, HER2 -) [36].

In transfected cells, there were no differences in Ki-67 staining pattern in comparison to control cells (Figure 6) and to the data gathered using MCF-7 cells (Figure 4). Nuclei morphology was not altered in transfected cells, but in some cases of cells expressing high levels of nuclear maspin, the cell nucleus was larger than in nontransfected cells. This may indicate polyploidy of these cells. After $48 \mathrm{~h}$ and $72 \mathrm{~h}$, most cells that lost Ki-67 expression revealed a high level of maspin in the nucleus (Figure 6).

The analyses of cells revealed, similarly to MCF-7 studies, that only nuclear maspin induces the loss of Ki-67 protein expression (Figure 6c,f). The majority of control, EGFP and maspin-EGFP cells in both cell lines expressed Ki-67 from $24 \mathrm{~h}$ to $120 \mathrm{~h}$ after transfection and the Ki-67 protein staining pattern in these cells was similar to that of MCF-7 cells. It seems that in SKBR-3 cells and MDA-MB-231 cells, the loss of Ki-67 expression in cells with nuclear maspin occurs later after transfection compared to MCF-7. In MCF-7 cell line, a decrease in Ki-67-positive cells expressing nuclear maspin was observed at $72 \mathrm{~h}$ after transfection, while in SKBR-3 and MDA-MB-231 cell lines gradual loss of Ki-67 expression was noted after $96 \mathrm{~h}$.

\section{Nuclear maspin does not affect proliferation of normal epithelial cells.}

The antiproliferative effect of nuclear maspin on breast cancer cell lines shows optimistic prospects for use of nuclear maspin as a potential genetic drug for breast cancer treatment. In order to test the effect of nuclear maspin on normal cell proliferation and potential unspecific cytotoxicity for normal breast cells we chose the epithelial normal cell line MCF10A. This cell line is ER-, PR- HER2- [36] and expresses maspin which locates more or less uniformly in the cytoplasm (Figure 7c).

The level of expression of endogenous maspin in this cell line is several-fold lower than that achieved by transient expression of maspin using our constructs. Similarly to previous cell lines transfection of MCF10A cells with EGFP, maspin-EGFP and maspin-NLS-EGFP does not significantly affect the phenotype of cells. There is also no difference in number of Ki-67 protein-positive cells between control cells and those with EGFP, 
Figure 4 Analyses of Ki-67 protein expression in MCF-7 cells with expression of EGFP, maspin-EGFP and maspin-NLS-EGFP. Cells were transiently transfected with plasmids containing transgenes: EGFP, maspin-EGFP and maspin-NLS-EGFP. a, b - Cells fixed at $48 \mathrm{~h}$ and $96 \mathrm{~h}$ after transfection. a - 48 hours after transfection some cells expressing high levels of maspin localized in nucleus demonstrate reduction in Ki-67 protein; $\mathbf{b}$ - after 96 hours the subpopulation of cells with nuclear maspin expressing Ki-67 is decreased; at the same time there are no significant differences in control cells and cells transfected with EGFP and maspin-EGFP localized in cytoplasm; c - magnification of cells with nuclear localization of maspin at 24 to 120 hours after transfection and gradual loss of Ki-67 protein; arrows show cells expressing nuclear maspin that lost Ki-67 protein.

cytoplasmic maspin and nuclear maspin, especially during the first three days after transfection. After that time the number of Ki-67 protein positive cells varies in different transfections but changes are not statistically significant (Figure 7a, b and d). The decrease in number of Ki-67 protein-positive cells from $96 \mathrm{~h}$ to $120 \mathrm{~h}$ is the result of increased confluence of cells since normal epithelial cells are more susceptible to overpopulation and contact inhibition than breast cancer cells. We believe that these higher deviation errors arise from the contact inhibition since MCF10A control cells (data not shown) also show similar effects after 96 and $120 \mathrm{~h}$.

The lack of inhibition of proliferation of MCF10A cells by maspin indicates that antiproliferative activity of nuclear maspin is restricted solely to/against breast cancer cells. This indicates that nuclear maspin may be used as a genetic drug in breast cancer treatment.

\section{Discussion}

In many publications the various maspin localization has been confirmed, including the nuclear localization, which initially was ignored as an artifact $[18,19,37]$. Nuclear maspin localization was observed in breast, prostate, lung, colorectal, pancreas and larynx cancers [19,20,23-26,37].

Even if the anticancer effect of the nuclear fraction of maspin has been described in some reports, the precise significance of the maspin expression level and subcellular localization is still not completely understood. Moreover, recent reports on maspin function have focused on cytoplasmic maspin or undirected maspin introduction into the cells, which resulted in its cytoplasmic location $[30,31,37]$. Also the biological function of maspin and its influence on degree of differentiation, stage and invasiveness of cancer are not clearly established. Therefore we decided to investigate the effect of maspin localization on breast cancer with reference to clinical data from breast cancer specimens from patients (Figure 1).

Many reports have suggested that biological of maspin in various types of cancer depend on its subcellular localization [19-22]. Therefore, maspin protein level was 


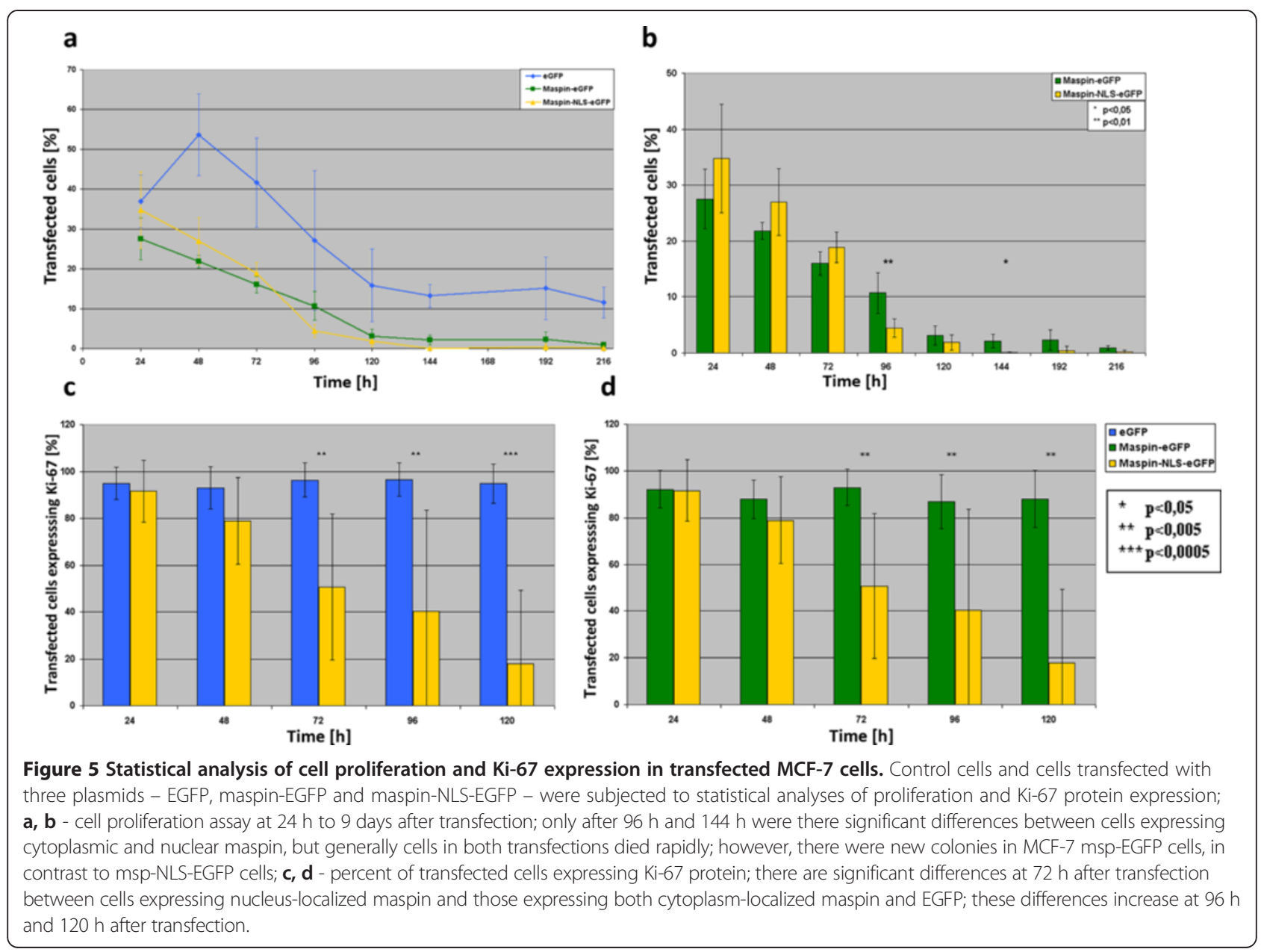

evaluated independently in cytoplasm and nucleus in each specimen from patients.

In our study, a positive reaction to maspin was demonstrated in most specimens $-89.2 \%$. A mixed reaction, localized both in nucleus and cytoplasm, was observed in most cases; only cytoplasmic localization was observed in $21.1 \%$ of cases and only nuclear in $13.3 \%$. Similar data were obtained in studies in ovarian cancer, where most cases of low grading tumor exhibited maspin expression and most of them showed nuclear reaction [32]. In other studies on breast cancer specimens, about $96 \%$ of samples showed nuclear maspin expression and a cytoplasmic signal was present in 35\% of the cases [19].

To evaluate the effect of maspin localization on cell proliferation, the proliferation status of cells in samples from patients was determined by immunohistochemical staining for Ki-67 protein (Figure 1j,k). The expression of proliferation marker $\mathrm{Ki}-67$ is one of the main indicators of tumor cell proliferation and tumor grading. Moreover, it is used as a prognostic factor that helps to predict an outcome of cancer treatment [33,38]. Results obtained in our study indicated a statistically significant correlation between higher level of maspin protein in nuclei and decreased number of cells expressing Ki-67 (Figure 2c,d). These data suggest that the nuclear fraction of maspin has a strong influence on proliferation status of breast cancer cells in breast tissue, inhibiting their growth and division. The cytoplasmic fraction of maspin seems to have either an opposite effect than the nuclear pool or have no significant effect on proliferation status of breast cancer cells. Analyses of the Kaplan-Meier data indicated that in a time span of 25 years, lack of cytoplasmic maspin is beneficial over cytoplasmic maspin (Figure 2a,b). Also total lack of maspin is beneficial over low level of nuclear maspin (cumulative survival index 0.7 versus 0.2 ). The demonstrated correlation indicates the functional significance of each pool of maspin and suggests that maspin level and location may be considered for use as a prognostic marker as well.

To validate and compare results obtained in clinical studies, we decided to establish an in vitro model for assessing the functional significance of nuclear and cytoplasmic localization of maspin in breast cancer cell lines: 


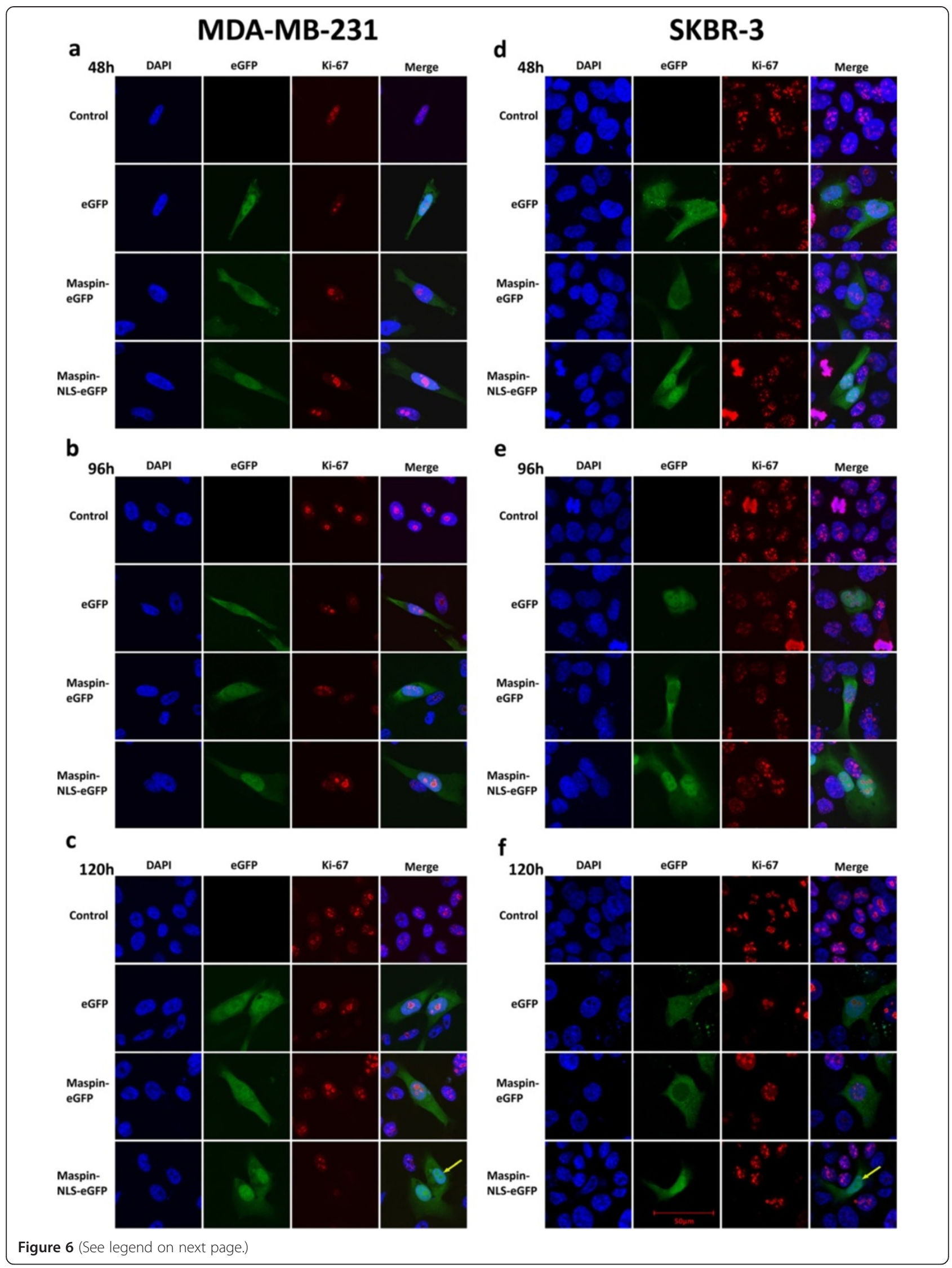


(See figure on previous page.)

Figure 6 Analysis of Ki-67 protein expression in MDA-MB-231 and SKBR-3 cells with various localization of maspin. Cells were transiently transfected with plasmids EGFP, maspin-EGFP and maspin-NLS-EGFP and fixed 24 to 120 hours later; $\mathbf{a}, \mathbf{b}, \mathbf{d}$, e - the majority of cells transfected with all three constructs express Ki-67 protein at $48 \mathrm{~h}$ and $96 \mathrm{~h}$ after transfection; $\mathbf{c}, \mathbf{f}$ - the majority of cells expressing nucleus-localized maspin do not express Ki-67 at $120 \mathrm{~h}$ after transfection; simultaneously there is no such observation in control cells and cells expressing EGFP and msp-EGFP localized in cytoplasm; arrows show cells expressing nuclear maspin that lost Ki-67 protein.

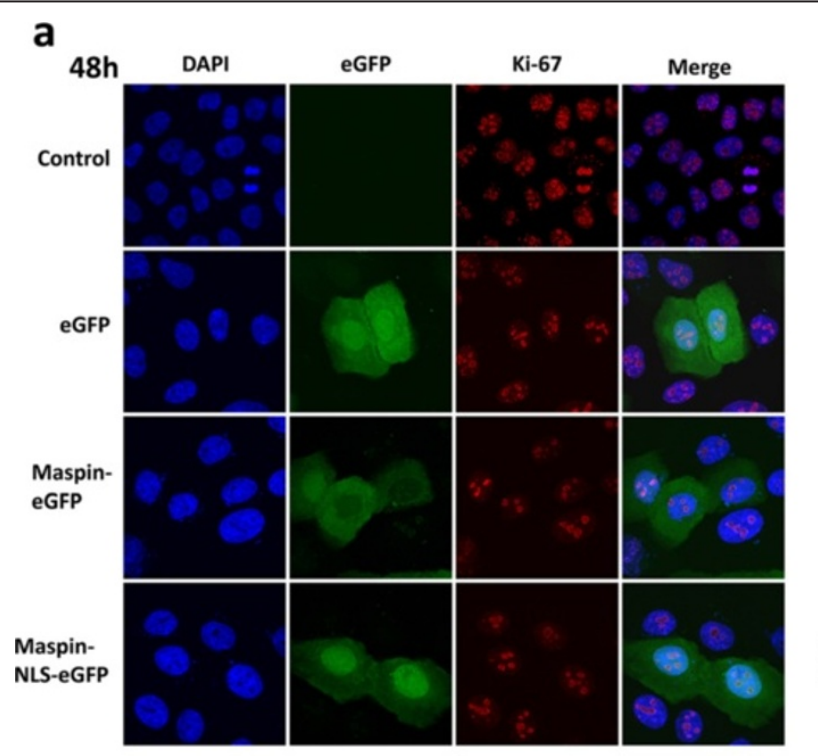

b

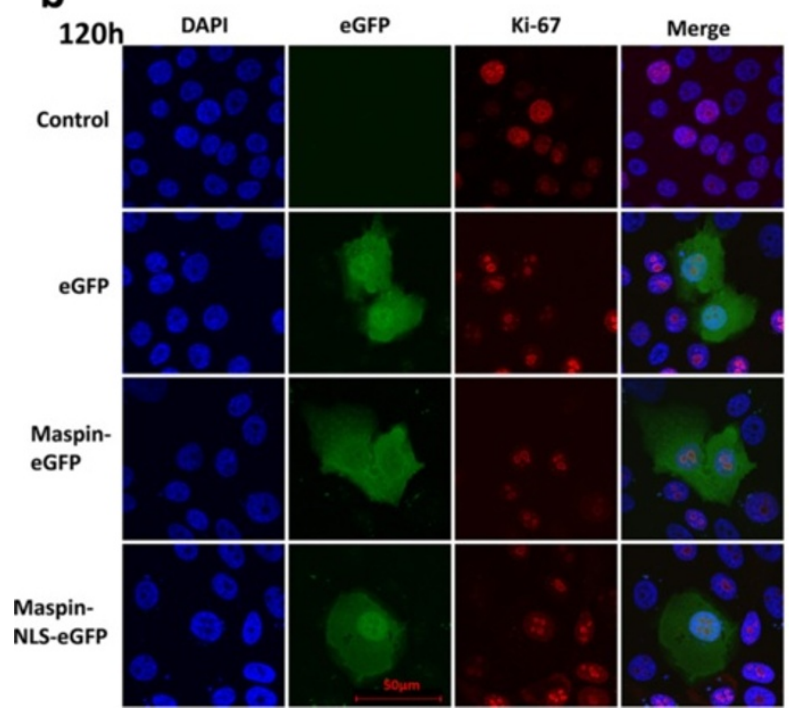

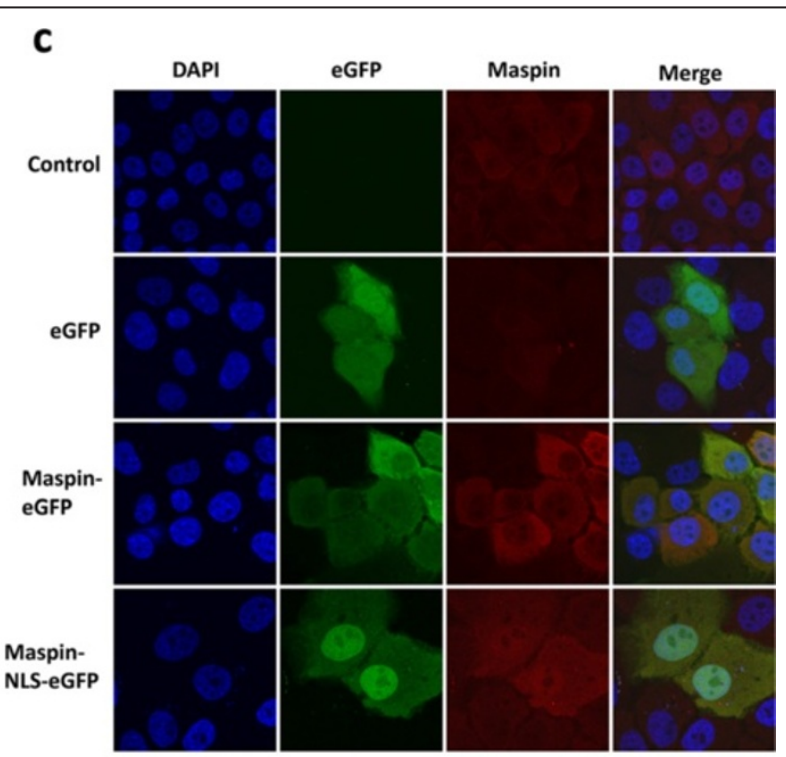

d

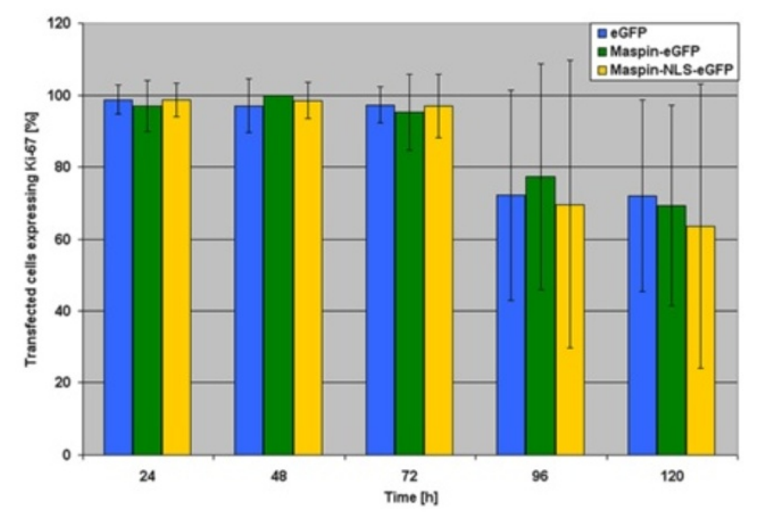

Figure 7 Ki-67 protein expression in MCF10A cells with various localization of maspin. Cells were transfected with plasmids EGFP, maspin-EGFP and maspin-NLS-EGFP and fixed after 24 to 120 hours; $\mathbf{a}, \mathbf{b}$ - the majority of cells transfected with all three constructs express Ki-67 protein at 48 h and $120 \mathrm{~h}$ after transfection; c - maspin localization in MCF10A cells after transfection; MCF10A cell line expresses endogenous maspin which is mostly localized in cytoplasm; $\mathbf{d}$ - statistical analysis of Ki-67 expression in MCF10A cells transfected with three plasmids; there are no significant differences at $24 \mathrm{~h}$ to $120 \mathrm{~h}$ after transfection between cells expressing nucleus-localized maspin and those expressing both cytoplasm-localized maspin and EGFP. 
MCF-7, MDA-MB-231 and SKBR-3. We also used normal epithelial cell line MCF10A as a control for normal breast tissue. These breast cancer cell lines do not express endogenous maspin because of its silencing mainly by epigenetic processes: CpG island methylation and histone deacetylation [39,40]. Control, normal cell line MCF10A does express maspin but at a relative moderate level and the protein is rather uniformly distributed in the cytoplasm.

All of the previously used methods of maspin reexpression or overexpression $[32,41,42]$ in tumors and breast cancer cell lines had some disadvantages. Classical cDNA transfection, transduction by adenoviruses, protein administration and re-expression by artificial transcription factors resulted in cytoplasmic or extracellular localization of maspin. Such in vitro experimental models did not address properly the problem of dual maspin location observed in breast cancer tissues. That is why our major aim was to develop an easy and appropriate model for studies of the effect of differently located maspin fractions on breast cancer cell lines.

In order to devise a simple model system allowing for controlled placement of maspin in cytoplasm and cell nucleus, we used EGFP protein as a fusion tag. EGFP protein (27 kDa, no NLS and NES signals) alone is capable of twoway diffusion through nuclear pore complexes [43]. Our model allows for active transport of maspin with fusion protein but prevents free diffusion. For driving maspinEGFP fusion protein into the cell nucleus we added a NLS signal sequence in a short linker protein fragment between maspin and EGFP (Figure $3 \mathrm{~b}$ ) to allow for proper folding of maspin and the EGFP part of the protein.

Analyses of location of maspin fusion proteins in MCF-7 cells using confocal microscopy fully supported our idea of driving maspin fusion proteins to the cytoplasm and nucleus using EGFP and NLS (Figure 3c).

In other breast cancer cell lines (SKBR-3 and MDA$\mathrm{MB}-231)$ the expression level of maspin fusion protein was similar but the ratio between nuclear and cytoplasmic fractions of maspin NLS-EGFP fusion proteins was a little lower (lower efficiency of maspin placement to targeted location) (Figure 6). This effect may be caused by maspin retention or active transport by binding/interacting proteins. MCF10A cells show a similar ratio between the nuclear and cytoplasmic maspin protein (Figure 7c). When both endogenous and exogenous maspin is analyzed using antibodies against maspin protein the lower efficiency of maspin placement to the targeted location is achieved since endogenous maspin locates in cytoplasm (Figure 7c). Thus in transfected MCF10A cells the level of maspin protein in nuclei is comparable with all other cancer cell lines tested while cytoplasmic maspin (endogenous and exogenous together) is roughly about $10-20 \%$ higher than in tested cancer cell lines.
Taking the observations together, we successfully constructed a simple, efficient and complete model to study the influence of maspin localization on breast cancer cell growth, which can be used for further studies using transient transfection.

Usefulness of this model was confirmed during our attempts to select cancer cell lines expressing nuclear maspin (maspin-NLS-EGFP), which failed completely and always within 2-3 weeks of selection. Since it was possible to select many cell lines expressing cytoplasmic maspin (Figure $3 \mathrm{~d}$ ) this demonstrated from the beginning the different and anti-proliferative activity of nuclear maspin. However, obtaining clones expressing maspin-EGFP required a longer period of time and lower concentration of selection antibiotic (because of cell death) than EGFP clones. Moreover, after transfection and a couple of days of selection, there were more EGFP-positive proliferating clones than in maspin-EGFP, despite the transfection efficiency being similar. Therefore, overexpression of maspin localized in cytoplasm may lead to slowdown of cell proliferation.

Nevertheless, there was no evidence that it was caused directly by a negative effect of cytoplasmic maspin on cells. It may be a result of overexpression of a larger protein with some biological functions, whilst EGFP is smaller and should not interfere with any cellular processes. However, previous reports demonstrated that exogenous maspin protein addition or transfection with plasmid encoding maspin (cytoplasmic location) resulted in increased cell sensitivity to cytotoxic agents, increased cell adhesion and inhibition of proliferation [42,44].

Proliferation assays and Ki-67 protein staining performed on MCF-7 breast cancer cell line indicated that the antiproliferative activity of maspin is the strongest in cells with nuclear maspin. For this reason, we have not been able to generate a stable breast cancer cell line expressing maspin localized in the nucleus and it does not allow us for precise studies of signaling pathways triggered by maspin. In the literature, there was no information about attempts of generation of a stable cell line with nuclear maspin, so it seems that this was the very first attempt to do so. Perhaps the generation of such a stable cell line will be possible only when maspin-NLS will be under a strictly controlled inducible promoter.

Anti-proliferative activity of nuclear maspin on MCF-7 cells (Figures 4 and 5) was confirmed on other breast cancer cell lines: SKBR-3 cells and highly invasive MDAMB-231 cell line (Figure 6). This indicates that nuclear maspin may be used as a prognostic marker and possibly as a therapeutic agent for cancer treatment using engineered maspin cDNA, for obtaining nuclear location of maspin, as a genetic drug in gene therapy.

In order to confirm the potential usefulness of nuclear maspin as a genetic drug we tested its potential negative 
effect on normal breast tissue using normal epithelial cell line MCF10A. This normal breast tissue cell line expresses maspin which is located mostly in cytoplasm (Figure 7c). Transient expression of maspin did not have any significant effect on proliferation of MCF10A cells or the number of Ki-67 protein expressing cells (Figure 7a,b,d), thus confirming the high potential of nucleus-directed maspin as an anticancer agent in gene therapy. But still, the major question of what is the molecular mechanism of maspin action remains unanswered.

The major difficulty clouding the biological activity of maspin is lack of sufficient knowledge of molecular mechanisms regulating maspin subcellular location in normal and cancer tissues. In the maspin protein sequence, neither characteristic domains nor sequences which may target maspin to the nucleus were found. Passive transport to the nucleus is rather unlikely due to maspin's weight $(42 \mathrm{kDa})$ and structure. This is verified experimentally since simple expression of maspin cDNA in many cancer cells results in cytoplasmic location of the protein. EGFP (27 kDa) expression results in dual nucleo-cytoplasmic location.

Many proteins may be translocated to the nucleus as a result of phosphorylation, for example the transcription factors IRF (interferon regulatory factors) [45]. Maspin, in its structure, has many potential phosphorylation sites. In vitro studies on mammary epithelial cells transfected with maspin indicate that maspin protein is phosphorylated by a kinase domain from the epidermal growth factor receptor (EGFR) [46]. This may regulate interaction of maspin with its binding partners which in turn, depending on their function and modifications, may translocate to and from the cell nucleus, affecting maspin location. On the other hand, maspin presence in a particular fraction may modulate the activity of interacting protein.

Proteins that may directly interact with maspin are not well known, although some studies in recent years suggest direct interaction of maspin with proteins associated with oxidative stress (GST - glutathione S-transferase) [47], heat shock proteins (HSP), histone deacetylase (HDAC1histone deacetylase I) [48], and IRF6 (interferon regulatory factor 6) [48], possibly indirectly affecting function of such transcription factors as Egr-1 and CGF2 [48]. Moreover, maspin may indirectly modulate the pro-apoptotic protein BAX (Bcl-2-associated X protein) [30], increase expression of the antiangiogenic thrombospondin and affect the expression of E2F1 [49,50]. Maspin is also implied in increase of expression of proteins from chromatin remodeling complex SMARCA2 and decreased expression of cytokines inducing inflammation and cell proliferation [49]. There was also observed maspin association with chromatin at the promoter of colony-stimulating factor-1 (CSF-1), which caused inhibition of tumor growth [22].
Some of these interactions may play an important role in maspin antiproliferation activity or maspin translocation to the cell nucleus.

The most interesting crosstalk between breast cancer cell proliferation and maspin offers two interactions of maspin: with IRF6 transcription factor and with HDAC1 in a GST-dependent manner. IRF6 promotes changes in cell adhesion, mobility and cell cycle probably (among others) through cadherin and vimentin. IRF6 locates both in cytoplasm and cell nucleus and interacts with maspin only when it is phosphorylated [51]. Recent studies demonstrated that IRF phosphorylation and subsequent proteasomal degradation are associated with induction of proliferation in normal breast epithelial cells (MCF10A). Concomitantly with this in breast cancer cell lines (MCF-7 and MDA-MD-231) overexpression of IRF6 together with maspin (located cytoplasmically) induced a synergistic effect of inhibition of proliferation but not total inhibition of proliferation [52]. This result resembles our data on proliferation slowdown by cytoplasmic maspin (Figure 5a,b).

The second directly interacting partner is HDAC1 complexed with GST. Cytoplasmic maspin may sequester complexes containing HDAC1 and GST and modulating its transport to nucleus and activity. Nuclear maspin may inhibit HDAC1 in a GST-dependent manner (oxidative stress sensitive) and prevent chromatin remodeling and change in transcription in an oxidative dependent manner [28].

The intriguing question is whether the loss of Ki-67 protein in cells with nuclear maspin is the cause or the result of the anti-proliferative effect of nuclear maspin on cells. The presence of Ki-67 protein is commonly used as a proliferation marker but its cellular functions are diverse and complex. During interphase it plays a crucial role in structural organization of nuclei, transcription and splicing of ribosomal RNA. The function of Ki-67 protein during mitosis is not fully understood but it belongs to the group of chromosomal passenger proteins and is located on mitotic chromosomes during mitosis [33,38]. Moreover, Ki-67 is necessary for forming a proper connection between microtubules and chromosome and for correct mitosis [53]. The time frame of cell death of nuclear maspin-containing cells fits exactly the 3 -day interval between loss of Ki-67 protein (72 h) and cell death (144 h) (Figures 4, 5, and 6).

Exogenous and cytoplasmic maspin may increase cell adhesion by activation of ERK1/2 and MAP kinases and independently the PI3K pathway (through atypical PKCzeta) and inhibit cell mobility by inhibition of Rac1 and PAK1 pathways. Increased cell adhesion may cause inhibition of cell proliferation [31,54]. Therefore, overexpression of maspin localized in cytoplasm may lead to slowdown of cell proliferation, which may explain why 
breast cancer cells transfected with maspin-EGFP (cytoplasmic maspin) slow down proliferation but do not stop proliferating. Unfortunately, current knowledge of maspin does not provide any sufficient explanations for the function of nuclear maspin in complete blocking of proliferation of breast cancer cell lines in our model system. Since we also demonstrated that nuclear maspin is crucial for better prognosis and inhibition of proliferation of breast tumors in vivo it suggests that nuclear maspin may be successfully used as a prognostic marker and potential genetic drug for gene therapy for breast cancer.

\section{Conclusions}

Our results indicate that nuclear maspin localization may be a prognostic factor in breast cancer and may have a strong therapeutic potential. High level of nuclear maspin is associated with better survival among breast cancer patients and lower proliferation status; thus nuclear maspin can be considered as a new marker of good prognosis of breast cancer. We also observed the inhibitory effect of nuclear maspin on cell proliferation in vitro in the three most frequently used breast cancer cell line models (MCF-7, SKBR-3 and MDA-MB-231), while there was no effect on proliferation of normal MCF10A breast cells. Maspin localization in the cell nucleus correlates with consecutive loss of Ki-67 protein, cell proliferation inhibition and cell death. Our data suggest a strong potential of nuclear maspin in breast cancer gene therapy treatment and provide a new insight into the role of maspin in breast cancer.

\begin{abstract}
Abbreviations
BAX: BCl-2-associated X protein; CSF-1: Colony-stimulating factor-1; DAB: 3,3'-diaminobenzidine; DMEM: Dulbecco's modified Eagle's medium; EGFP: Enhanced Green Fluorescent Protein; EGFR: Epidermal growth facto receptor; Egr-1: Early growth response protein 1; EMEM: Eagle's minimum essential medium; ER: Estrogen receptor; ERK1/2: Extracellular signal-regulated kinase 1/2; GCF2: GC-binding factor 2; GST: Glutathione S-transferase; HDAC1: Histone deacetylase 1; HER2: Human Epidermal Growth Factor Receptor 2; HSP: Heat shock proteins; IRF6: Interferon regulatory factor 6; Kip 1: Cyclin-dependent kinase inhibitor p27; NLS: Nuclear localization signal; NPCs: Nuclear pore complexes; PAK1: p21 protein activated kinase 1; PI3K: Phosphatidylinositide 3-kinases; PKCzeta: Protein kinase C isotype zeta; PR: Progesterone receptor; Rac1: Ras-related C3 botulinum toxin substrate 1; STAT3: Signal transducer and activator of transcription 3; WAP: Whey acidic protein.
\end{abstract}

\section{Competing interests}

Ryszard Rzepecki, Miroslaw Sopel and Wrocław Medical University have applied for a patent entitled. "The polypeptide containing nucleus-directed maspin and its application in anticancer therapy" (Patent Application Serial number P.397195). MS has received salary from Wrocław Medical University during this study. We have no other competing interests to declare.

\section{Authors' contributions}

MM, KW, MS, and RR participated in designing of the study. MM, KW, MS and RR participated in data analysis and drafting the manuscript. MM and RR wrote the manuscript. MM generated stable cell lines, cultured cells, stained cells after transfection for immunofluorescence, performed the immunofluorescence analysis, carried out the cell proliferation assay, performed the statistical analysis. KW constructed plasmids, inserted NLS by mutagenesis, cultured cells, generated stable cell lines. MS performed $\mathrm{IHC}$ staining of samples from patients, evaluated maspin's expression level and localization in these samples and provided statistical analysis of $\mathrm{HC}$ results. RR supervised the study, participated in data analysis and interpretation of results and coordinate experiments. All authors read and approved the final version of the manuscript. All authors fulfill all requirements for authorship.

\section{Acknowledgements}

We would like to thank Dr. Pawel Surowiak for providing breast cancer cell lines and the normal epithelial cell line from breast. We also would like to thank Pathology Department of Lower Silesia Cancer Center for histologically evaluaed, archived specimens from patients. This work was partially supported by the Polish Ministry of Science and Higher Education "Statutory Grant (1013/S/WB/2011-2013) and Wroclaw Research Centre EIT + under the project "Biotechnologies and advanced medical technologies" BioMed (POIG.01.01.02-02-003/08) (for MM and RR), financed by the European Regional Development Fund (Operational Programme Innovative Economy, 1.1.2). Funding bodies had no influence on design, analysis and interpretation of data as well as in writing the manuscript and decision for publication.

\section{Author details}

${ }^{1}$ Laboratory of Nuclear Proteins, Faculty of Biotechnology, University of Wroclaw, 63/77 Przybyszewskiego Street, 51-148 Wrocław, Poland.

2Department of Biology and Botanical Pharmacy, Medical University, 211 Borowska Street, 50-556 Wrocław, Poland. ${ }^{3}$ Present address: Division of Translational Cell Genetics, Department for Pharmacology and Genetics, Medical University of Innsbruck, 1a Peter Mayr Street, A-6020 Innsbruck, Austria.

Received: 22 July 2013 Accepted: 11 February 2014

Published: 28 February 2014

\section{References}

1. Zou Z, Anisowicz A, Hendrix MJ, Thor A, Neveu M, Sheng S, Rafidi K, Seftor E, Sager R: Maspin, a serpin with tumor-suppressing activity in human mammary epithelial cells. Science 1994, 263(5146):526-529.

2. Pemberton PA, Wong DT, Gibson HL, Kiefer MC, Fitzpatrick PA, Sager R, Barr PJ: The tumor suppressor maspin does not undergo the stressed to relaxed transition or inhibit trypsin-like serine proteases. Evidence that maspin is not a protease inhibitory serpin. J Biol Chem 1995, 270(26):15832-15837.

3. Sternlicht MD, Kedeshian P, Shao ZM, Safarians S, Barsky SH: The human myoepithelial cell is a natural tumor suppressor. Clin Cancer Res 1997, 3(11):1949-1958.

4. Pemberton PA, Tipton AR, Pavloff N, Smith J, Erickson JR, Mouchabeck ZM, Kiefer MC: Maspin is an intracellular serpin that partitions into secretory vesicles and is present at the cell surface. J Histochem Cytochem 1997, 45(12):1697-1706.

5. Gao F, Shi HY, Daughty C, Cella N, Zhang M: Maspin plays an essential role in early embryonic development. Development 2004, 131(7):1479-1489.

6. Zhang M, Magit D, Botteri F, Shi HY, He K, Li M, Furth P, Sager R: Maspin plays an important role in mammary gland development. Dev Biol 1999 215(2):278-287.

7. Maass N, Hojo T, Rosel F, Ikeda T, Jonat W, Nagasaki K: Down regulation of the tumor suppressor gene maspin in breast carcinoma is associated with a higher risk of distant metastasis. Clin Biochem 2001, 34(4):303-307.

8. Jiang N, Meng Y, Zhang S, Mensah-Osman E, Sheng S: Maspin sensitizes breast carcinoma cells to induced apoptosis. Oncogene 2002, 21(26):4089-4098.

9. Zhang M, Volpert O, Shi YH, Bouck N: Maspin is an angiogenesis inhibitor. Nat Med 2000, 6(2):196-199.

10. Hojo T, Akiyama Y, Nagasaki K, Maruyama K, Kikuchi K, Ikeda T, Kitajima M, Yamaguchi K: Association of maspin expression with the malignancy grade and tumor vascularization in breast cancer tissues. Cancer Lett 2001, 171(1):103-110.

11. Zhang M, Maass N, Magit D, Sager R: Transactivation through Ets and Ap1 transcription sites determines the expression of the tumor-suppressing gene maspin. Cell Growth Differ 1997, 8(2):179-186.

12. Domann FE, Rice JC, Hendrix MJ, Futscher BW: Epigenetic silencing of maspin gene expression in human breast cancers. Int J Cancer 2000 85(6):805-810.

13. Stark AM, Schem C, Maass N, Hugo HH, Jonat W, Mehdorn HM, Held-Feindt $\mathrm{J}$ : Expression of metastasis suppressor gene maspin is reduced in breast 
cancer brain metastases and correlates with the estrogen receptor status. Neurol Res 2010, 32(3):303-308.

14. Maass N, Hojo T, Ueding M, Luttges J, Kloppel G, Jonat W, Nagasaki K: Expression of the tumor suppressor gene Maspin in human pancreatic cancers. Clin Cancer Res 2001, 7(4):812-817.

15. Xia W, Lau YK, Hu MC, Li L, Johnston DA, Sheng S, El-Naggar A, Hung MC: High tumoral maspin expression is associated with improved survival of patients with oral squamous cell carcinoma. Oncogene 2000, 19(20):2398-2403.

16. Umekita $Y$, Yoshida $H$ : Expression of maspin is up-regulated during the progression of mammary ductal carcinoma. Histopathology 2003, 42(6):541-545.

17. Bieche I, Girault I, Sabourin JC, Tozlu S, Driouch K, Vidaud M, Lidereau R: Prognostic value of maspin mRNA expression in ER alpha-positive postmenopausal breast carcinomas. Br J Cancer 2003, 88(6):863-870.

18. Maass $N$, Teffner M, Rosel F, Pawaresch $R$, Jonat W, Nagasaki $K$, Rudolph P: Decline in the expression of the serine proteinase inhibitor maspin is associated with tumour progression in ductal carcinomas of the breast. J Pathol 2001, 195(3):321-326.

19. Mohsin SK, Zhang M, Clark GM, Craig Allred D: Maspin expression in invasive breast cancer: association with other prognostic factors. J Pathol 2003, 199(4):432-435

20. Lonardo F, Li X, Siddiq F, Singh R, Al-Abbadi M, Pass HI, Sheng S: Maspin nuclear localization is linked to favorable morphological features in pulmonary adenocarcinoma. Lung Cancer 2006, 51(1):31-39.

21. Solomon LA, Munkarah AR, Schimp VL, Arabi MH, Morris RT, Nassar H, Ali-Fehmi R: Maspin expression and localization impact on angiogenesis and prognosis in ovarian cancer. Gynecol Oncol 2006, 101(3):385-389.

22. Goulet B, Kennette W, Ablack A, Postenka CO, Hague MN, Mymryk JS, Tuck $A B$, Giguere V, Chambers AF, Lewis JD: Nuclear localization of maspin is essential for its inhibition of tumor growth and metastasis. Lab Invest 2011, 91(8):1181-1187.

23. Sopel M, Surowiak P, Berdowska I: Nuclear maspin expression as a good prognostic factor in human epithelial ovarian carcinoma. Folia Morphol (Warsz) 2010, 69(4):204-212.

24. Marioni G, Blandamura S, Giacomelli L, Calgaro N, Segato P, Leo G, Fischetto $D$, Staffieri A, de Filippis C: Nuclear expression of maspin is associated with a lower recurrence rate and a longer disease-free interval after surgery for squamous cell carcinoma of the larynx. Histopathology 2005, 46(5):576-582.

25. Blandamura S, Giacomelli L, Leo G, Segato P, Ninfo V: Nuclear maspin detection in renal cell tumours: possible diagnostic role and correlation with p53 status. Histopathology 2006, 49(3):274-282.

26. Dietmaier W, Bettstetter M, Wild PJ, Woenckhaus M, Rummele P, Hartmann A, Dechant S, Blaszyk H, Pauer A, Klinkhammer-Schalke M, Hofstadter F: Nuclear Maspin expression is associated with response to adjuvant 5 -fluorouracil based chemotherapy in patients with stage III colon cancer. Int J Cancer 2006, 118(9):2247-2254.

27. Zhang W, Shi HY, Zhang M: Maspin overexpression modulates tumor cel apoptosis through the regulation of $\mathrm{BCl}-2$ family proteins. BMC Cancer 2005, 5:50.

28. Li X, Kaplun A, Lonardo F, Heath E, Sarkar FH, Irish J, Sakr W, Sheng S: HDAC1 inhibition by maspin abrogates epigenetic silencing of glutathione $\mathrm{S}$ transferase pi in prostate carcinoma cells. Mol Cancer Res 2011, 9(6):733-745.

29. Beltran AS, Russo A, Lara H, Fan C, Lizardi PM, Blancafort P: Suppression of breast tumor growth and metastasis by an engineered transcription factor. PLoS One 2011, 6(9):e24595.

30. Liu J, Yin S, Reddy N, Spencer C, Sheng S: Bax mediates the apoptosissensitizing effect of maspin. Cancer Res 2004, 64(5):1703-1711.

31. Odero-Marah VA, Khalkhali-Ellis Z, Chunthapong J, Amir S, Seftor RE, Seftor EA, Hendrix MJ: Maspin regulates different signaling pathways for motility and adhesion in aggressive breast cancer cells. Cancer Biol Ther 2003, 2(4):398-403

32. Sood AK, Fletcher MS, Gruman LM, Coffin JE, Jabbari S, Khalkhali-Ellis Z, Arbour N, Seftor EA, Hendrix MJ: The paradoxical expression of maspin in ovarian carcinoma. Clin Cancer Res 2002, 8(9):2924-2932.

33. Wiesner FG, Magener A, Fasching PA, Wesse J, Bani MR, Rauh C, Jud S, Schrauder M, Loehberg CR, Beckmann MW, Hartmann A, Lux MP: Ki-67 as a prognostic molecular marker in routine clinical use in breast cancer patients. Breast 2009, 18(2):135-141.

34. Kill IR: Localisation of the Ki-67 antigen within the nucleolus. Evidence for a fibrillarin-deficient region of the dense fibrillar component. J Cell SCi 1996, 109(Pt 6):1253-1263.
35. Bullwinkel J, Baron-Luhr B, Ludemann A, Wohlenberg C, Gerdes J, Scholzen $\mathrm{T}$ : Ki-67 protein is associated with ribosomal RNA transcription in quiescent and proliferating cells. J Cell Physio/ 2006, 206(3):624-635.

36. Subik K, Lee JF, Baxter L, Strzepek T, Costello D, Crowley P, Xing L, Hung MC, Bonfiglio T, Hicks DG, Tang P: The Expression Patterns of ER, PR, HER2, CK5/6, EGFR, Ki-67 and AR by Immunohistochemical Analysis in Breast Cancer Cell Lines. Breast Cancer (Auckl) 2010, 4:35-41.

37. Machtens S, Serth J, Bokemeyer C, Bathke W, Minssen A, Kollmannsberger C, Hartmann J, Knuchel R, Kondo M, Jonas U, Kuczyk M: Expression of the p53 and Maspin protein in primary prostate cancer: correlation with clinical features. Int J Cancer 2001, 95(5):337-342.

38. de Azambuja E, Cardoso F, de Castro G Jr, Colozza M, Mano MS, Durbecq V, Sotiriou C, Larsimont D, Piccart-Gebhart MJ, Paesmans M: Ki-67 as prognostic marker in early breast cancer: a meta-analysis of published studies involving 12,155 patients. Br J Cancer 2007, 96(10):1504-1513.

39. Wu Y, Alvarez M, Slamon DJ, Koeffler P, Vadgama JV: Caspase 8 and maspin are downregulated in breast cancer cells due to $\mathrm{CpG}$ site promoter methylation. BMC Cancer 2010, 10:32.

40. Dokras A, Coffin J, Field L, Frakes A, Lee H, Madan A, Nelson T, Ryu GY, Yoon JG: Epigenetic regulation of maspin expression in the human placenta. Mol Hum Reprod 2006, 12(10):611-617.

41. Murakami J, Asaumi J, Maki Y, Tsujigiwa H, Kuroda M, Nagai N, Yanagi Y, Inoue T, Kawasaki S, Tanaka N, Matsubara N, Kishi K: Effects of demethylating agent 5-aza-2(')-deoxycytidine and histone deacetylase inhibitor FR901228 on maspin gene expression in oral cancer cell lines. Oral Oncol 2004, 40(6):597-603

42. Li Z, Shi HY, Zhang M: Targeted expression of maspin in tumor vasculatures induces endothelial cell apoptosis. Oncogene 2005, 24(12):2008-2019.

43. Wei $X$, Henke VG, Strubing C, Brown EB, Clapham DE: Real-time imaging of nuclear permeation by EGFP in single intact cells. Biophys J 2003, 84(2 Pt 1):1317-1327.

44. Shi HY, Zhang W, Liang R, Kittrell F, Templeton NS, Medina D, Zhang M: Modeling human breast cancer metastasis in mice: maspin as a paradigm. Histol Histopathol 2003, 18(1):201-206.

45. Bailey CM, Hendrix MJ: IRF6 in development and disease: a mediator of quiescence and differentiation. Cell Cycle 2008, 7(13):1925-1930.

46. Odero-Marah VA, Khalkhali-Ellis Z, Schneider GB, Seftor EA, Seftor RE, Koland $J G$, Hendrix MJ: Tyrosine phosphorylation of maspin in normal mammary epithelia and breast cancer cells. Biochem Biophys Res Commun 2002, 295(4):800-805.

47. Yin S, Li X, Meng Y, Finley RL Jr, Sakr W, Yang H, Reddy N, Sheng S Tumor-suppressive maspin regulates cell response to oxidative stress by direct interaction with glutathione S-transferase. J Biol Chem 2005, 280(41):34985-34996.

48. Li X, Yin S, Meng Y, Sakr W, Sheng S: Endogenous inhibition of histone deacetylase 1 by tumor-suppressive maspin. Cancer Res 2006, 66(18):9323-9329.

49. Bailey CM, Khalkhali-Ellis Z, Seftor EA, Hendrix MJ: Biological functions of maspin. J Cell Physiol 2006, 209(3):617-624

50. Ben Shachar B, Feldstein O, Hacohen D, Ginsberg D: The tumor suppressor maspin mediates E2F1-induced sensitivity of cancer cells to chemotherapy. Mol Cancer Res 2010, 8(3):363-372.

51. Bailey CM, Khalkhali-Ellis Z, Kondo S, Margaryan NV, Seftor RE, Wheaton WW, Amir S, Pins MR, Schutte BC, Hendrix MJ: Mammary serine protease inhibitor (Maspin) binds directly to interferon regulatory factor 6: identification of a novel serpin partnership. J Bio/ Chem 2005, 280(40):34210-34217.

52. Bailey CM, Abbott DE, Margaryan NV, Khalkhali-Ellis Z, Hendrix MJ: Interferon regulatory factor 6 promotes cell cycle arrest and is regulated by the proteasome in a cell cycle-dependent manner. Mol Cell Biol 2008, 28(7):2235-2243.

53. Vanneste D, Takagi M, Imamoto N, Vernos I: The role of Hklp2 in the stabilization and maintenance of spindle bipolarity. Curr Biol 2009, 19(20):1712-1717

54. Shi HY, Stafford LJ, Liu Z, Liu M, Zhang M: Maspin controls mammary tumor cell migration through inhibiting Rac1 and Cdc42, but not the RhoA GTPase. Cell Motil Cytoskeleton 2007, 64(5):338-346.

\section{doi:10.1186/1471-2407-14-142}

Cite this article as: Machowska et al:: Nuclear location of tumor suppressor protein maspin inhibits proliferation of breast cancer cells without affecting proliferation of normal epithelial cells. BMC Cancer 2014 14:142. 